Article

\title{
Communication Performance Assessment for Advanced Metering Infrastructure
}

\author{
Jen-Hao Teng * , Chia-Wei Chao, Bin-Han Liu, Wei-Hao Huang and Jih-Ching Chiu \\ Departmental of Electrical Engineering, National Sun Yat-Sen University, Kaohsiung 80424, Taiwan; \\ chiawei6846@gmail.com (C.-W.C.); kev810106@gmail.com (B.-H.L.); eric12142002@hotmail.com (W.-H.H.); \\ chiujihc@ee.nsysu.edu.tw (J.-C.C.) \\ * Correspondence: jhteng@ee.nsysu.edu.tw; Tel.: +886-7-525-2000 (ext. 4118)
}

Received: 28 November 2018; Accepted: 25 December 2018; Published: 28 December 2018

\begin{abstract}
Advanced Metering Infrastructure (AMI), the foundation of smart grids, can be used to provide numerous intelligent power applications and services based on the data acquired from AMI. Effective and efficient communication performance between widely-spread smart meters and Data Concentrator Units (DCUs) is one of the most important issues for the successful deployment and operation of AMI and needs to be further investigated. This paper proposes an effective Communication Performance Index (CPI) to assess and supervise the communication performance of each smart meter. Some communication quality measurements that can be easily acquired from a smart meter such as reading success rate and response time are used to design the proposed CPI. Fuzzy logic is adopted to combine these measurements to calculate the proposed CPI. The CPIs for communication paths, DCUs and whole AMI can then be derived from meter CPIs. Simulation and experimental results for small-scale AMIs demonstrate the validity of the proposed CPI. Through the calculated CPIs, the communication performance and stability for AMI can be effectively assessed and supervised.
\end{abstract}

Keywords: Advanced Metering Infrastructure; Data Concentrator Unit; Communication Performance Index; reading success rate; response time

\section{Introduction}

The integration of renewable energy generation into power grids has been looked upon as one of the most effective and efficient methodologies to reduce carbon emissions from energy demand increases. However, the power output of renewable energy generation is quite stochastic with high uncertainty and raises difficulties in the planning and operation of power grids. Smart grids, integrated with new communication interfaces, smart sensing measurement technologies, advanced control strategies, intelligent decision supporting systems etc., are therefore considered to be the best way to facilitate the integration of renewable energy generation. A contemporary smart grid must at least include the functionalities of control and management for renewable energy generation, self-healing from power events, demand response for consumers, optimal power assent usage and management, new market service development and so on [1-5].

Due to the uncertainties and complexities of smart grids, the deployment of Advanced Metering Infrastructure (AMI) has been treated as the foundation for the realization of smart grids [6-11]. In general, AMI consists of smart meters, meter data management system, communication infrastructure etc. and can provide useful information based on the data acquired from smart meters to realize numerous intelligent controls and services for smart grids. For example, Reference [11] proposed two methods to discover abnormal electricity consumption by utilizing contextual and factual information from AMI, including energy consumption patterns, nature of supply and category 
of day to logically group meters. The AMI market has experienced a large growth in demand due to the increasing implementation of smart grid technology. The total number of smart meter installations in 2017 was close to 88.2 million and is predicted to reach a cumulative figure of over 588 million by 2022 [6]. Reference [7] forecasted that during the period 2017-2023, the worldwide AMI market is estimated to grow by 9 billion USD by 2023 at a compound annual growth rate of $14 \%$. Some countries including the US, Japan, South Korea and so on have legislated to achieve the target of $100 \%$ smart meter deployment. In 2012-2013, an AMI pilot project with about twelve-thousand smart meters has been deployed in Taiwan. Two hundred thousand smart meters are deployed now and this will grow in the next few years to five-million meters. Effective and efficient communication performance between widely-spread smart meters and Data Concentrator Units (DCUs), the core of data management in an AMI providing the technology to measure and collect energy usage data from smart meters to the meter data management system, is one of the most important issues for the successful deployment and operation of AMI. If the communication performance and stability is poor, all AMI functionalities cannot be successfully realized [8-24]. Wire and wireless communications are both the commonly-used communication interfaces. Wire communication with huge construction costs has the advantage of high reliability. The conventional wireless communication techniques have the disadvantages of lower reliability, lower data rate, uncertain time-delay etc. The recent local-area-network communications such as ZigBee and Power Line Communication (PLC), also used in Taiwan's AMI, have been verified to be suitable for the communication network of AMI between the smart meters and DCUs. Some new ZigBee and PLC techniques are still being developed, for example, Reference [15] proposed a new PLC-based smart metering architecture. The coupling interfaces were experimentally verified in a wide frequency range up to $200 \mathrm{kHz}$ using different modulations.

Many papers have been published to discuss the communication deployment for AMI [12-24]. Most of the published papers focused on the issues of data acquisition point placement, routing protocol, delay analysis etc. for AMI communication networks [12-18]; however, these proposed technologies are not suitable for communication performance assessment. Few papers proposed the methodologies suitable to evaluate the communication performance before AMI deployment [19-24]; however, the question of how to supervise the communication performance continuously still needs to be further investigated. Some methodologies based on the Gale-Shapley algorithm were proposed to analyze the capacity sharing for a set of geographically distributed independent items to integrate their resources and demand forecasts for a specific production objective $[25,26]$. The communication performance assessment wasn't included in the proposed capacity sharing. This paper proposed an effective Communication Performance Index (CPI) to assess on a daily basis and supervise the communication performance of each smart meter after the AMI has been implemented. Some useful communication quality measurements that can be easily acquired from a smart meter such as reading success rate and response time are used to design the proposed CPI. The reading success rate is used to record meter reading success rate on a per hour, day or month basis. A higher reading success rate usually indicates the better stability of a communication network. The response time is the elapsed time between the end of an inquiry on a DCU or meter data management system and the beginning of a response. Faster response time also implies a higher communication performance. Fuzzy logic is employed to integrate these measurements into the proposed CPI calculation. The CPIs for communication paths, DCUs and whole AMI can then be derived from meter CPIs. Simulation and experimental results for small-scale AMIs demonstrate the validity of the proposed CPI. The main contributions of this paper include:

- Using some communication quality measurements easily acquired from a smart meter to design a CPI.

- Through the calculated CPIs, the communication performance and stability of AMI can be effectively assessed and supervised.

- The proposed CPI and communication performance assessment would be supportive of the future deployment and operation of AMI. 


\section{Design of an Effective CPI}

Many communication quality parameters such as the link quality indicator, received signal strength indicator, signal-to-noise ratio, reading error rate etc. are commonly used to define the performance of a communication network. However, the response time of a smart meter is an essential factor to determine the response speed of the smart meter in the communication network. Besides, the reading success rate of a smart meter, used to make sure whether the reading process was successful, is also an important factor for observing the stability of a communication network. The response time and reading success rate are easily acquired from a smart meter and therefore are adopted in this paper to assess the communication performance. The CPI adopting those factors for a single smart meter is derived first, the CPIs for DCUs and AMI are then developed. Most smart meters in an AMI provide meter data every $15 \mathrm{~min}$; therefore, the total reading number is 96 in a day. If the meter data are completely received by the meter data management system, then it will be counted as a successful reading. The reading success rate of a smart meter in a period of one day can be expressed as

$$
R S R(\%)=\frac{N R S}{96} \times 100 \%
$$

where NRS is the number of reading successes. $R S R(\%)$ is the reading success rate. If the number of reading successes is 95 , the reading success rate is $98.96 \%$.

The average response time of a day can also be calculated by

$$
R T(m s)=\frac{\sum_{i \in \Phi_{N R S}} R T(i)}{N R S} \times 100 \%
$$

where $R T(m s)$ is the average response time. $R T(i)$ is the response time for the $i^{\text {th }}$ reading success. $\Phi_{N R S}$ is the set of reading success number in a day.

Since at least daily response time and reading success rate acquired from a smart meter are adopted to assess the CPI and the absolute correlation between these two factors is difficult to undoubtedly determine, fuzzy logic is employed in this paper to integrate these two factors into the proposed CPI calculation. Fuzzy logic has been widely used in solving many industrial control and quality problems [27-30]. Figure 1 shows the procedures of fuzzy logic realized for the proposed CPI. The reading success rate and response time of a smart meter are used as input variables and passed through the fuzzifier. The fuzzy rules and inference engine act like an expert to adjust the weightings between the input variables and then the defuzzifier scores the CPI for the meter. A triangular membership function with five levels, Negative Big (NB), Negative Small (NS), Zero (ZE), Positive Small (PS) and Positive Big (PB), is used in this paper. Figure 2 illustrates the membership functions used to fuzzify and defuzzify the input and the output variables. $\mu_{R S R}, \mu_{R T}$ and $\mu_{C P I}$ in Figure 2 indicate the membership functions for reading success rate, response time and CPI of a meter, respectively. As an example, the membership functions of reading success rate and response time are in the range of $80 \%$ to $99 \%$ and in the range of $200 \mathrm{~ms}$ to $400 \mathrm{~ms}$, respectively. Note that the ranges can be adjusted according to the actual communication network used. Variable membership functions including Gaussian, trapezoidal, polynomial etc. can also be adopted in calculating CPI without modifying the proposed procedures. 
Reading Success Rate

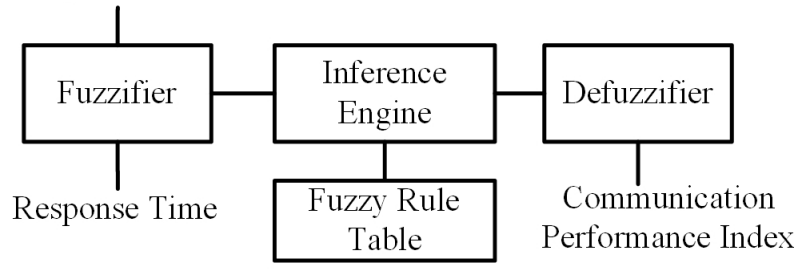

Figure 1. Fuzzy Logic Procedures for the Proposed CPI.

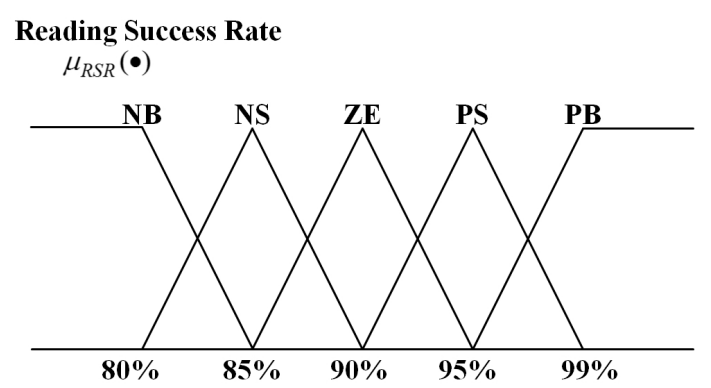

(a)
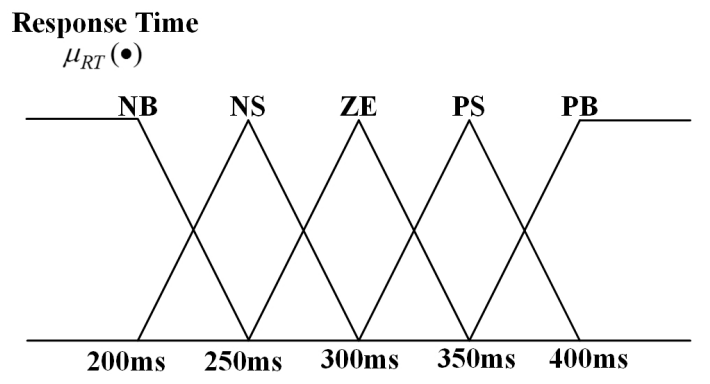

(b)

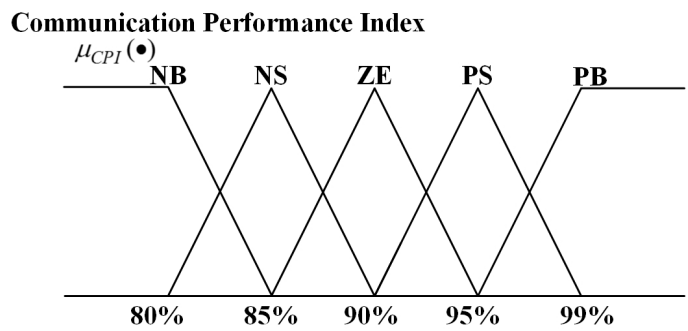

(c)

Figure 2. Membership Functions Used for Proposed CPI. (a) Reading Success Rate; (b) Response Time; (c) CPI.

Table 1 illustrates the fuzzy rules for the proposed CPI. The basic concept of fuzzy rules is that a higher reading success rate and lower response time should have a higher CPI. A minimum inference engine and center of gravity defuzzifier are used in this paper. Figure 3 shows the concept of a minimum inference engine. An example of this is if Rule 6 is activated and the values of $\mu_{R S R}$ and $\mu_{R T}$ are NS of 0.7 and NB of 0.3 , respectively. The minimum inference engine picks the smaller of the two; therefore, the result of Rule 6 will be NS of 0.3. The CPI defuzzified by center of gravity can be calculated by

$$
\mathrm{CPI}=\frac{\sum_{i} \mu_{C P I}\left(x_{i}\right) \times x_{i}}{\sum_{i} \mu_{C P I}\left(x_{i}\right)}
$$


Table 1. Fuzzy Rules for Proposed CPI.

\begin{tabular}{cccccc}
\hline \multirow{2}{*}{$R_{\text {SR }}^{*}$} & \multicolumn{5}{c}{$\boldsymbol{R T}^{*}$} \\
\cline { 2 - 6 } & NB & NS & ZE & PS & PB \\
\hline \multirow{2}{*}{ NB } & Rule1 & Rule2 & Rule3 & Rule4 & Rule5 \\
& NB & NB & NB & NB & NB \\
NS & Rule6 & Rule7 & Rule8 & Rule9 & Rule10 \\
& NS & NS & NB & NB & NB \\
ZE & Rule11 & Rule12 & Rule13 & Rule14 & Rule15 \\
& ZE & ZE & NS & NS & NB \\
PS & Rule16 & Rule17 & Rule18 & Rule19 & Rule20 \\
& PS & PS & ZE & NS & NS \\
PB & Rule21 & Rule22 & Rule23 & Rule24 & Rule25 \\
& PB & PB & PS & ZE & ZE \\
\hline
\end{tabular}

* RT and RSR indicates response time and reading success rate, respectively.

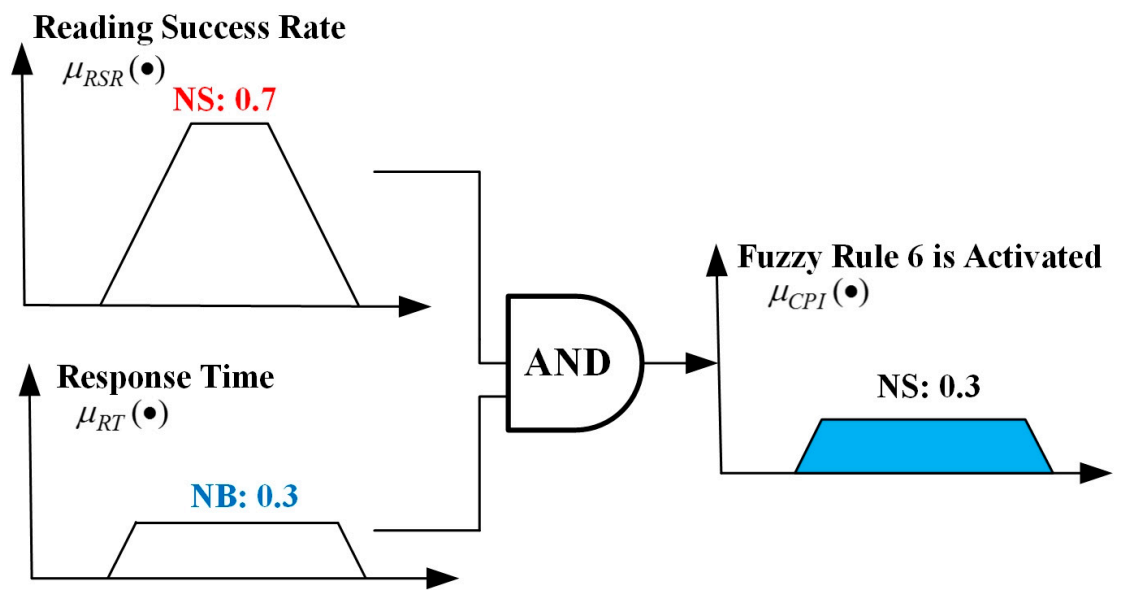

Figure 3. Concept of Minimum Inference Engine.

A simple example with a reading success rate of $98 \%$ and response time of $260 \mathrm{~ms}$, respectively is used to describe how to calculate the proposed CPI. Figure 4 shows the results through the fuzzifier. From Figure 4, it can be observed that the values of $\mu_{R S R}$ are PB of 0.75 and PS of 0.25 and the values of $\mu_{R T}$ are NS of 0.8 and ZE of 0.2. From Table 2, it can be observed that Rule 17, Rule 18, Rule 22 and Rule 23 are activated and the results obtained from minimum inference engine are

Rule 17: PS $=\min (0.25,0.80)=0.25$

Rule 18: $\mathrm{ZE}=\min (0.25,0.20)=0.20$

Rule 22: $\mathrm{PB}=\min (0.85,0.80)=0.80$

Rule 23: $P S=\min (0.85,0.20)=0.20$

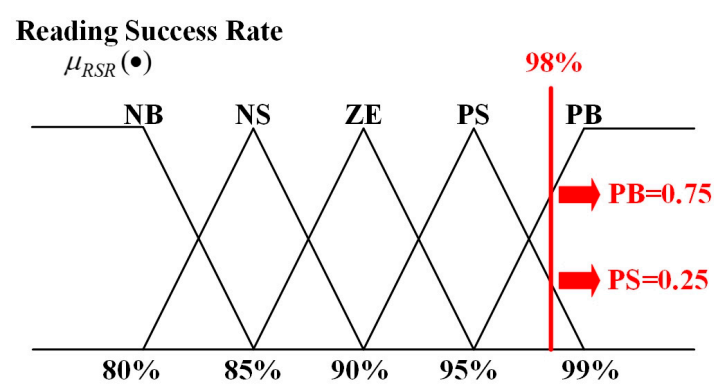

(a)

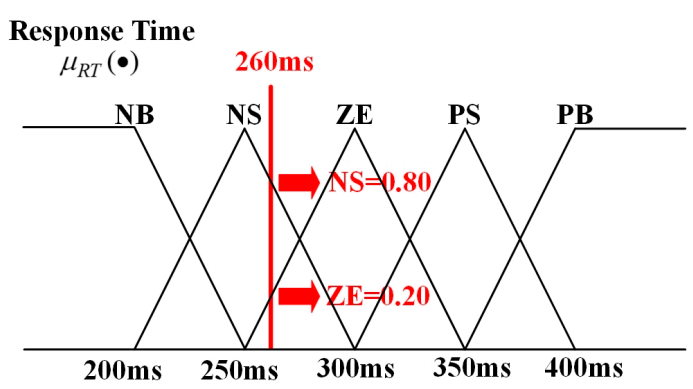

(b)

Figure 4. Minimum Inference Engine. (a) Reading Success Rate; (b) Response Rate. 
Table 2. Results of Activated Fuzzy Rules.

\begin{tabular}{cccccc}
\hline \multirow{2}{*}{ RSR } & \multicolumn{5}{c}{ RT } \\
\cline { 2 - 6 } & NB & NS & ZE & PS & PB \\
\hline \multirow{2}{*}{ NB } & Rule1 & Rule2 & Rule3 & Rule4 & Rule5 \\
& NB & NB & NB & NB & NB \\
NS & Rule6 & Rule7 & Rule8 & Rule9 & Rule10 \\
& NS & NS & NB & NB & NB \\
ZE & Rule11 & Rule12 & Rule13 & Rule14 & Rule15 \\
& ZE & ZE & NS & NS & NB \\
PS & Rule16 & Rule17 & Rule18 & Rule19 & Rule20 \\
& PS & PS $=$ min(0.25,0.80) & ZE $=$ min $(0.25,0.20)$ & NS & NS \\
PB & Rule21 & Rule22 & Rule23 & Rule24 & Rule25 \\
& PB & PB $=\min (0.85,0.80)$ & PS $=\min (0.85,0.20)$ & ZE & ZE \\
\hline
\end{tabular}

The results obtained from fuzzy rules and minimum inference engine are also drawn in Figure 5. The CPI defuzzified by the center of gravity from Figure 5 for the simple example is $95.18 \%$.

\section{Communication Performance Index}

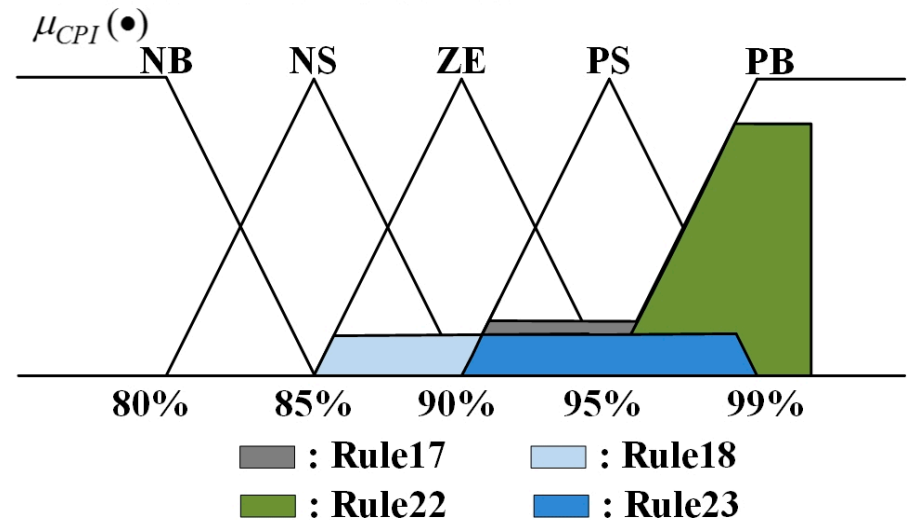

Figure 5. Results of Fuzzy Rules and Minimum Inference Engine.

\section{Communication Performance Assessment for AMI}

Through the proposed CPI of a smart meter, the CPI for the communication path between the meters can also be calculated. Using Figure 6 as an example, it can be obviously seen that the CPIs for communication paths between smart meters $M_{i}$ and $M_{k}$ and smart meters $M_{j}$ and $M_{k}$ are equal to the CPIs of $M_{i}$ and $M_{j}$, respectively. Therefore, the CPIs for communication paths between smart meters $M_{i}$ and $M_{k}$ and smart meters $M_{j}$ and $M_{k}$ can be expressed as

$$
\begin{aligned}
& \operatorname{CPI}\left(M_{i}, M_{k}\right)=\operatorname{CPI}\left(M_{i}\right) \\
& \operatorname{CPI}\left(M_{j}, M_{k}\right)=\operatorname{CPI}\left(M_{j}\right)
\end{aligned}
$$

where $\operatorname{CPI}\left(M_{x}\right)$ is the calculated CPI for smart meter $M_{x}$. CPI $\left(M_{x}, M_{y}\right)$ is the CPI for the communication path between smart meters $M_{x}$ and $M_{y}$.

A smart meter needs to send its own meter data to DCU; therefore, smart meter $M_{k}$ will act like a router and transmit the meter data received from smart meters $M_{i}$ and $M_{j}$ to DCU. The CPI for the communication path between DCU and smart meter $M_{k}$ can be calculated by the geometric average and is expressed as

$$
\mathrm{CPI}\left(M_{k}, D C U\right)=\frac{N_{i} \times \mathrm{CPI}\left(M_{i}\right)+N_{j} \times \mathrm{CPI}\left(M_{j}\right)+N_{k} \times \mathrm{CPI}\left(M_{k}\right)}{N_{i}+N_{j}+N_{k}}
$$


where $N_{x}$ is the number of data transmission from meter $M_{x}$.

Obviously, $\mathrm{CPI}\left(M_{k}, D C U\right)$ in Figure 6 can be determined as the CPI of this DCU.

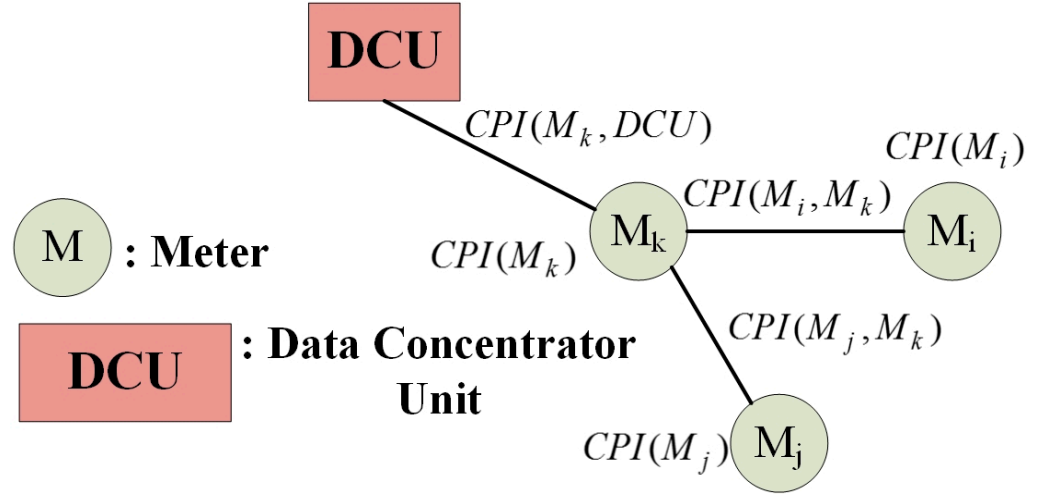

Figure 6. Part of Communication Network under DCU.

The above-mentioned procedure can be easily extended to assess the communication performance of an actual AMI. Figure 7 shows an actual small-scale PLC-based AMI acquired from the Institute for Information Industry of Taiwan, the CPI of each communication path can be calculated by

$$
\operatorname{CPI}\left(M_{x}, M_{y}\right)=\frac{\sum_{m \in \phi_{x y}} N_{m} \times \operatorname{CPI}\left(M_{m}\right)}{\sum_{m \in \phi_{x y}} N_{m}}
$$

where $\phi_{x y}$ indicates the meter set using the communication path between smart meter $M_{x}$ and $M_{y}$ to transmit data to DCU. $N_{m}$ is the number of data transmission for smart meter $M_{m}$ belonging to $\phi_{x y}$ and using the communication path between smart meters $M_{x}$ and $M_{y}$.

The CPI of each smart meter can be assessed first and then the CPIs for the communication paths, DCUs and whole AMI can be calculated accordingly based on the CPIs of smart meters. With the proposed communication performance assessment, the communication performance and stability for an AMI can be effectively supervised. 


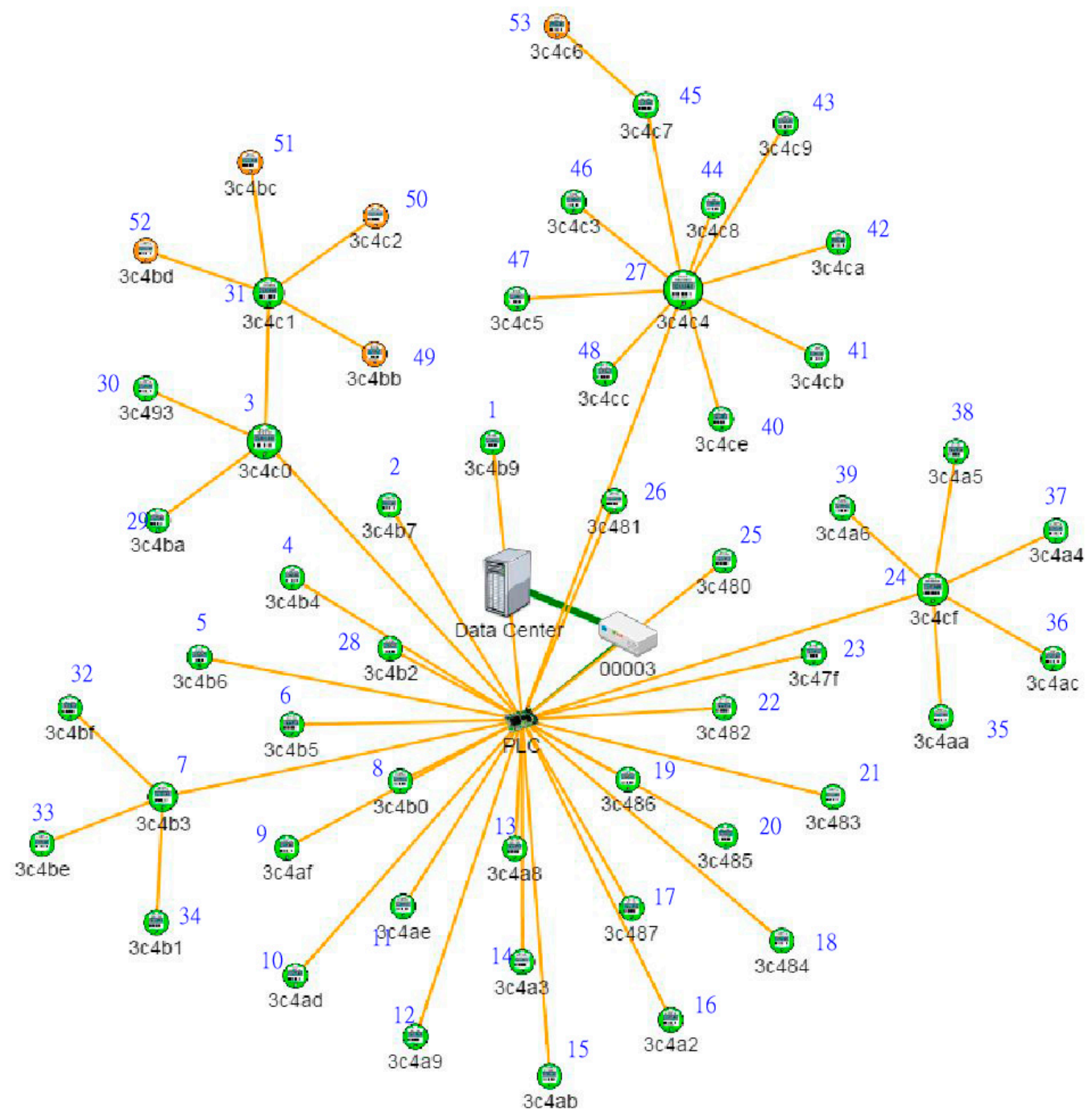

Figure 7. An Actual Small-Scale PLC-based AMI.

\section{Simulation and Experimental Results}

\subsection{A Simple Six-Meter Case}

Figure 8 shows the communication network configuration of a simple six-meter case used to clarify the basic concepts and implementation of proposed CPI. Table 3 shows the communication paths of the six-meter case. Figures 9 and 10 is the values and Probability Density (PD) of reading success rate and response time for smart meters $M_{1}$ and $M_{4}$. Due to limited space, the other data is not shown here. The CPIs calculated by the proposed method is shown in Figure 11. The CPIs of smart meters, communication paths and DCU can be easily observed from Figure 11. The number of each communication path used can be calculated and the results are as shown in Figure 12. From Figures 11 and 12 , it can be observed that smart meter $M_{5}$ with the communication path " $5 \rightarrow 4 \rightarrow$ DCU" has the lower CPI and the communication path between $M_{5}$ and DCU has higher CPI. Therefore, if the communication path of smart meter $M_{5}$ is changed to " $5 \rightarrow \mathrm{DCU}$ ", then the overall CPI may be increased. Figures 13 and 14 show the calculated CPI and the number of each communication path used after the communication paths of smart meter $M_{3}$ changed to " $3 \rightarrow 5 \rightarrow \mathrm{DCU}$ " and of smart meter $M_{5}$ changed to " $5 \rightarrow \mathrm{DCU}$ ", respectively. Figure 13 indicates that the CPIs with the changes of communication paths are enhanced; therefore, the proposed CPI and the number of each communication path used can be adopted to find the optimal communication path of each meter. This paper provides an 
effective mechanism to assess and supervise the communication performance of AMI, the optimal communication path selection integrating with other routing algorithms [12-18], [31-33] will be investigated in the future.

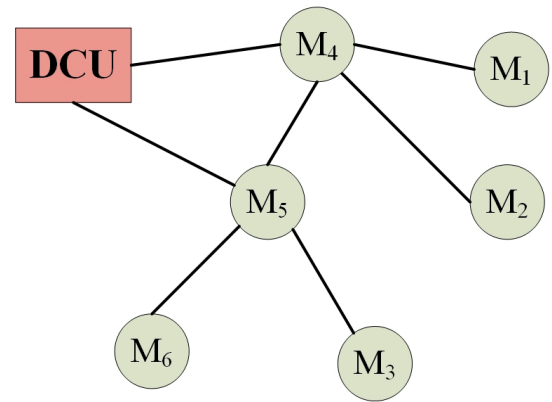

Figure 8. Communication Network of a Simple Six-Meter Case.

Table 3. Communication Paths of the Simple Six-Meter Case.

\begin{tabular}{cc}
\hline Meter & Communication Path \\
\hline 1 & $1 \rightarrow 4 \rightarrow$ DCU \\
2 & $2 \rightarrow 4 \rightarrow$ DCU \\
3 & $3 \rightarrow 5 \rightarrow 4 \rightarrow$ DCU \\
4 & $4 \rightarrow$ DCU \\
5 & $5 \rightarrow 4 \rightarrow$ DCU \\
6 & $6 \rightarrow 5 \rightarrow$ DCU \\
\hline
\end{tabular}

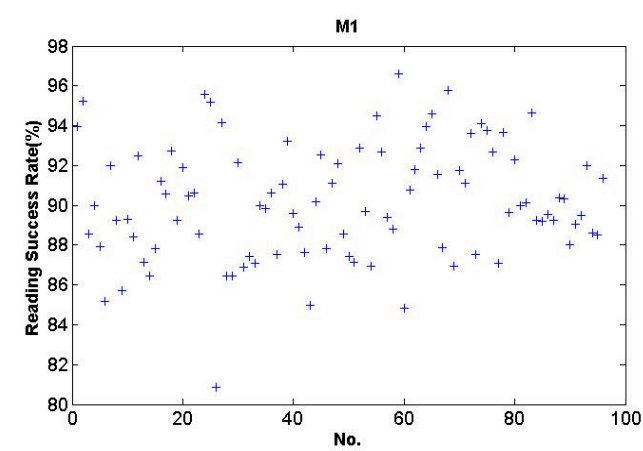

(a)

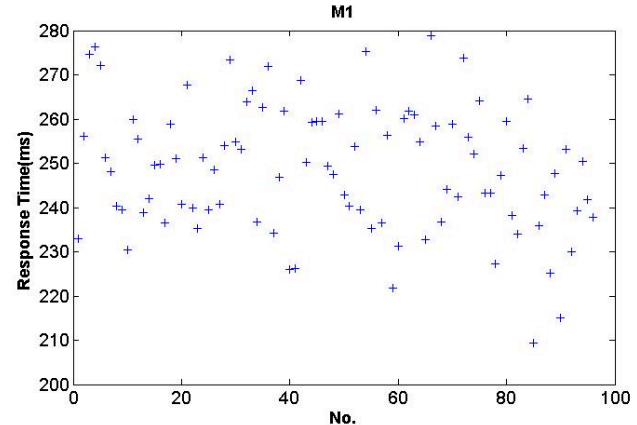

(c)

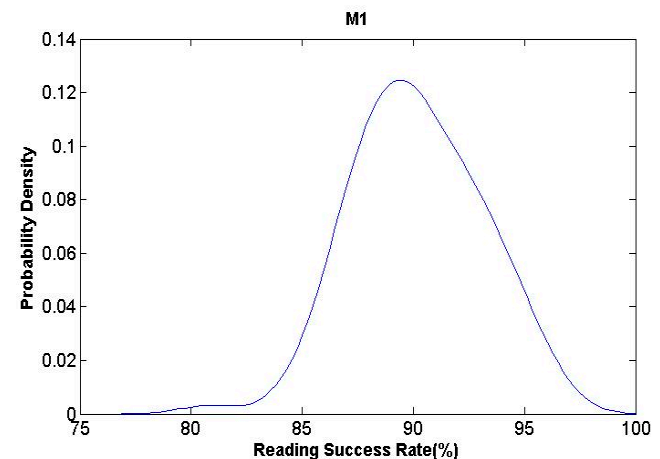

(b)

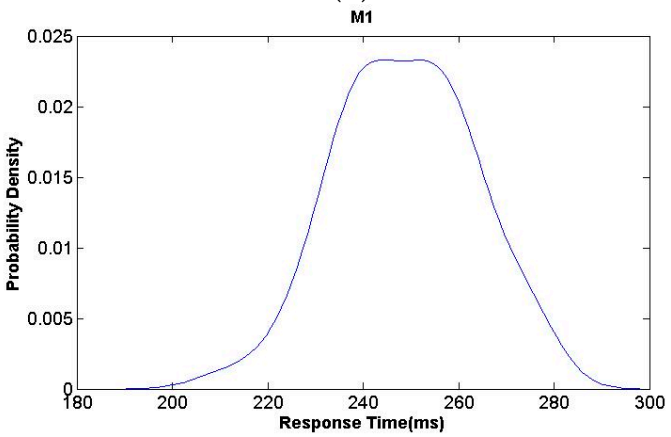

(d)

Figure 9. Measurements and PDs of $M_{1}$. (a) Reading Success Rate; (b) PD of Reading Success Rate; (c) Response Time; (d) PD of Response Time. 


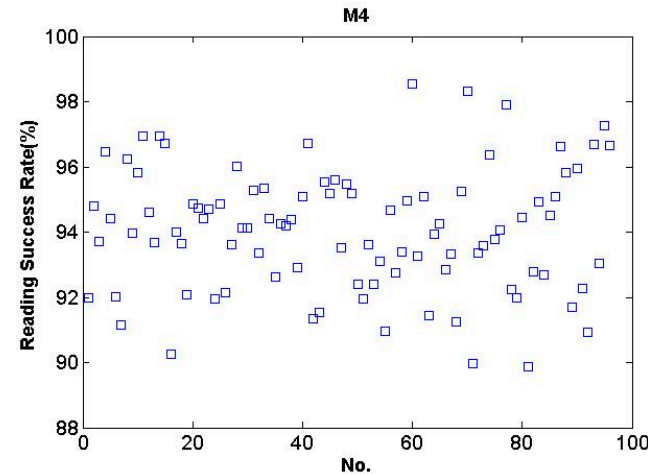

(a)

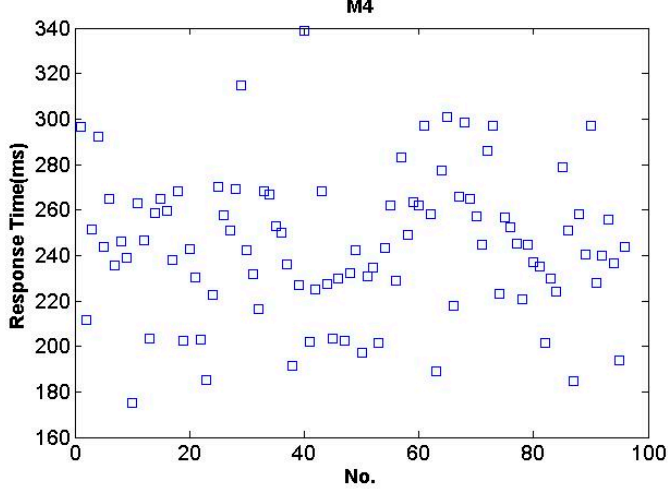

(c)

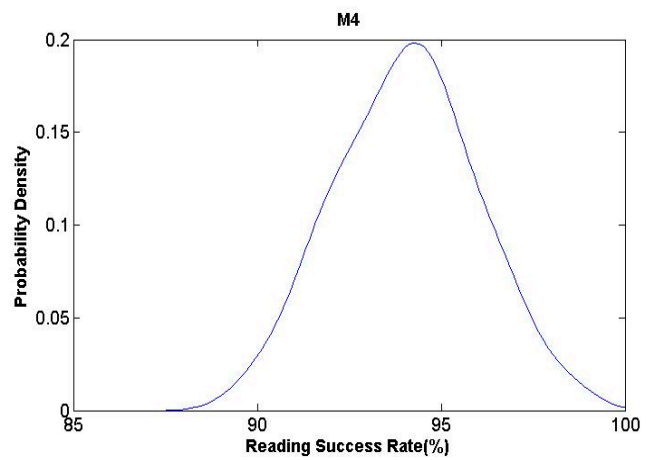

(b)

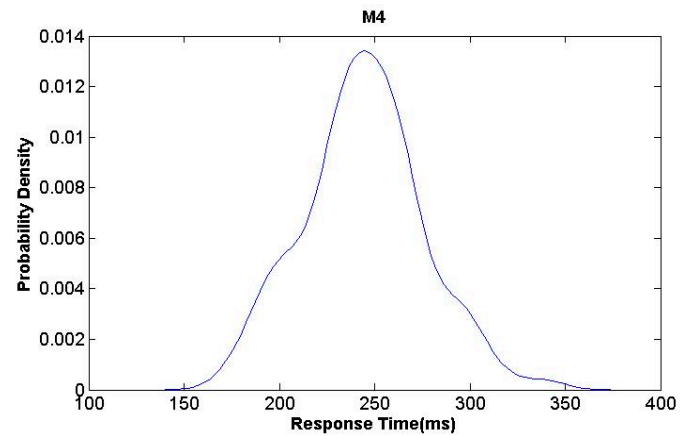

(d)

Figure 10. Measurements and PDs of $M_{4}$. (a) Reading Success Rate; (b) PD of Reading Success Rate; (c) Response Time; (d) PD of Response Time.

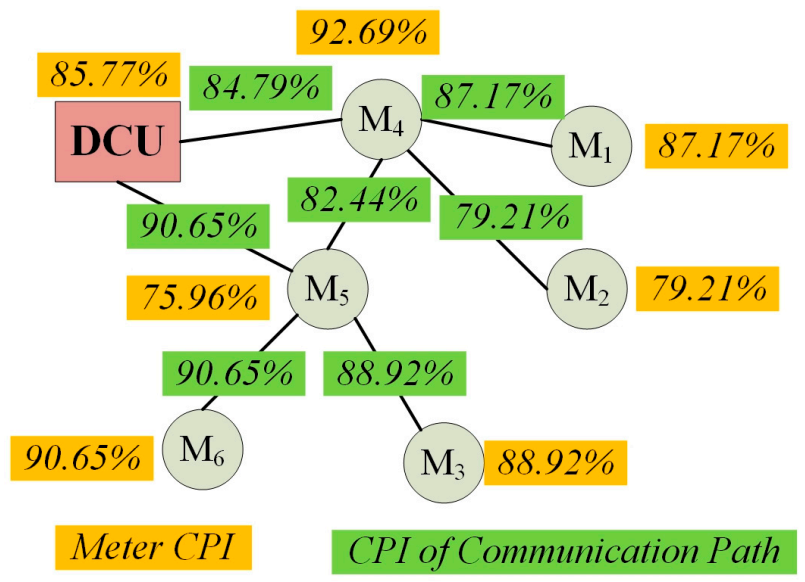

Figure 11. CPIs for the Six-Meter Case. 


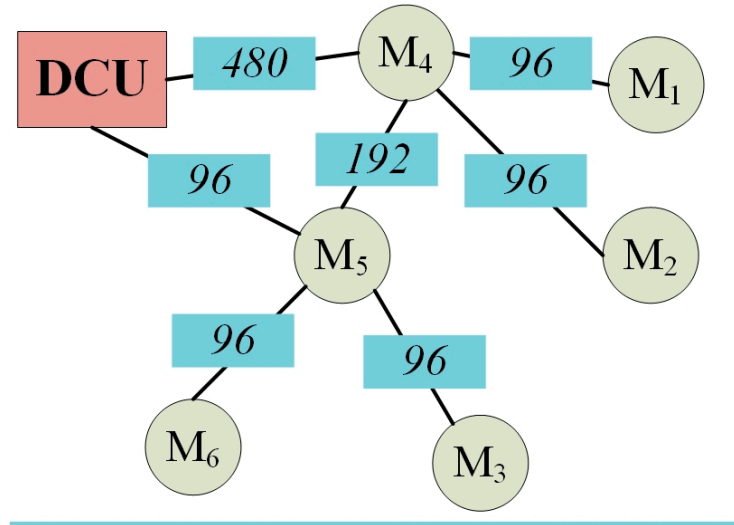

\section{Number of Communication Path Used}

Figure 12. Number of Communication Paths Used for the Six-Meter Case.

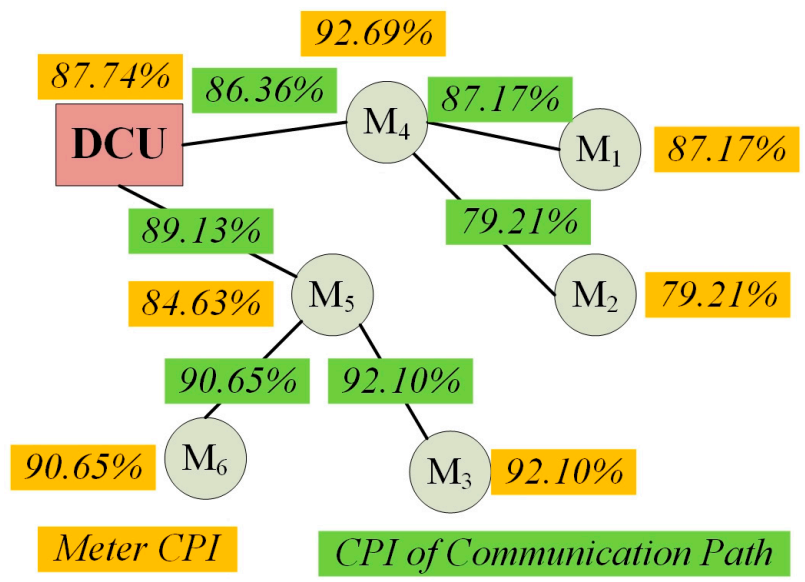

Figure 13. CPIs for the Six-Meter Case after Communication Path Changed.

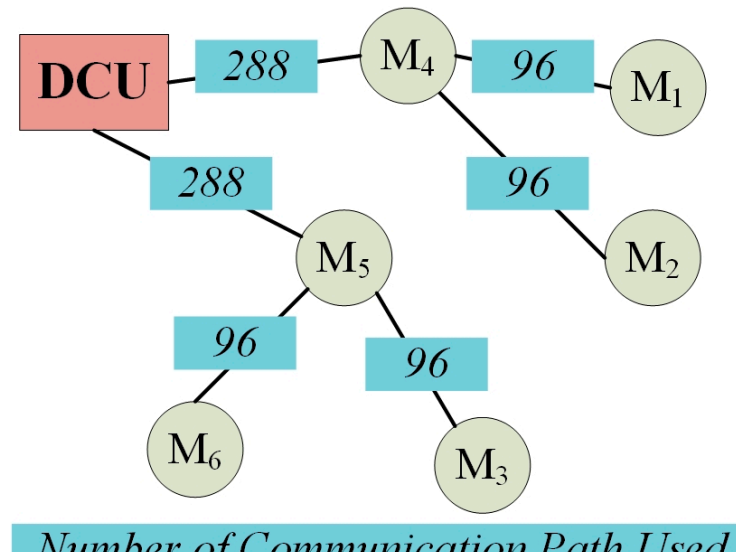

Figure 14. Number of Communication Paths Used for the Six-Meter Case after Communication Paths Changed.

\subsection{Field Measurements and Communmication Performance Assessment}

An actual small-scale PLC-based AMI as illustrated in Figure 7 is used to demonstrate the validity of the proposed CPI. For convenient observation, Figure 7 is redrawn as Figure 15 and the meters are renumbered and listed in Table 4. From Figure 15 and Table 4, it can be seen that there are $53 \mathrm{~m}$ and the DCU is used to collect energy usage data from these meters to the meter data management system. Smart meters $M_{3}, M_{7}, M_{24}, M_{27}, M_{31}$, and $M_{45}$ act like the routers and transmit the meter data 
received from other smart meters to DCU. Table 5 shows the field communication measurements of smart meter $M_{1}$ used in the proposed CPI calculation. From Table 5, it can be observed that the reading success rates are between $28.13 \%$ and $100 \%$ with average and standard deviation of $89.15 \%$ and $16.74 \%$, respectively. The reading success rate can be considered as an indicator of communication network stability. The response times are between $148.6 \mathrm{~ms}$ and $620 \mathrm{~ms}$, with an average and standard deviation of $331.72 \mathrm{~ms}$ and $114.63 \mathrm{~ms}$, respectively. The membership function of response time is designed in the range of $200 \mathrm{~ms}$ to $600 \mathrm{~ms}$ and is shown in Figure 16 from the field measurements. Figures 17 and 18 illustrates the calculated CPIs and calculated average CPIs for Day 1 and from Days 1 to 31, respectively. The average and standard deviation of meter CPIs from Days 1 to 31 are also listed in Table 6. Based on the calculated CPIs, the communication performance of each meter can be supervised. For example, Figure 19 shows the CPIs and 5-day average CPIs of smart meter $M_{1}$. From Figure 19, it can be observed that $M_{1}$ has worse CPIs in Days 14, 15, 19, 22, 23 and 24. The possible causes can be further investigated. Obviously, from Figures 17-19 and Table 6 the communication performance and stability of smart meter $M_{1}$ can be effectively and efficiently assessed and supervised. Since the field communication measurements used in the proposed CPI can be effortlessly acquired from smart meters, the proposed communication performance assessment has great potential to be integrated into a large-scale AMI to support its operation.

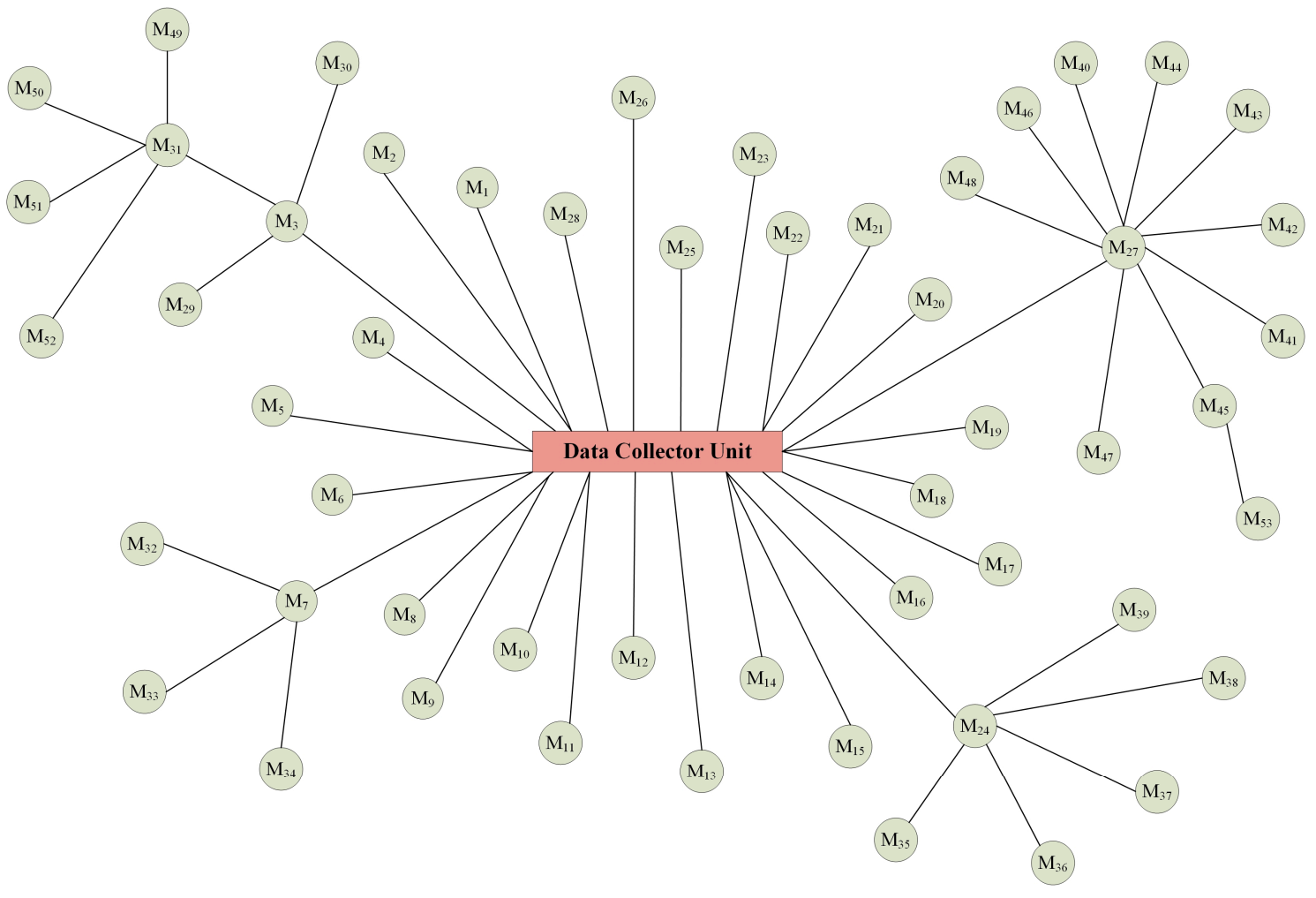

Figure 15. Communication Network Configuration of Actual Small-Scale PLC-based AMI. 
Table 4. Meter Number for the Actual Small-Scale PLC-based AMI.

\begin{tabular}{cccccccc}
\hline Meter & ID & Meter & ID & Meter & ID & Meter & ID \\
\hline 1 & $3 c 4 b 9$ & 15 & $3 c 4 a b$ & 29 & $3 c 4 b a$ & 43 & $3 c 4 c 9$ \\
2 & $3 c 4 b 7$ & 16 & $3 c 4 a 2$ & 30 & $3 c 493$ & 44 & $3 c 4 c 8$ \\
3 & $3 c 4 c 0$ & 17 & $3 c 487$ & 31 & $3 c 4 c 1$ & 45 & $3 c 4 c 7$ \\
4 & $3 c 4 b 4$ & 18 & $3 c 484$ & 32 & $3 c 4 b f$ & 46 & $3 c 4 c 3$ \\
5 & $3 c 4 b 6$ & 19 & $3 c 486$ & 33 & $3 c 4 b e$ & 47 & $3 c 4 c 5$ \\
6 & $3 c 4 b 5$ & 20 & $3 c 485$ & 34 & $3 c 4 b 1$ & 48 & $3 c 4 c c$ \\
7 & $3 c 4 b 3$ & 21 & $3 c 483$ & 35 & $3 c 4 a a$ & 49 & $3 c 4 b b$ \\
8 & $3 c 4 b 0$ & 22 & $3 c 482$ & 36 & $3 c 4 a c$ & 50 & $3 c 4 c 2$ \\
9 & $3 c 4 a f$ & 23 & $3 c 47 f$ & 37 & $3 c 4 a 4$ & 51 & $3 c 4 b c$ \\
10 & $3 c 4 a d$ & 24 & $3 c 4 c f$ & 38 & $3 c 4 a 5$ & 52 & $3 c 4 b d$ \\
11 & $3 c 4 a e$ & 25 & $3 c 480$ & 39 & $3 c 4 a 6$ & 53 & $3 c 4 c 6$ \\
12 & $3 c 4 a 9$ & 26 & $3 c 481$ & 40 & $3 c 4 c e$ & - & - \\
13 & $3 c 4 a 8$ & 27 & $3 c 4 c 4$ & 41 & $3 c 4 c b$ & - & - \\
14 & $3 c 4 a 3$ & 28 & $3 c 4 b 2$ & 42 & $3 c 4 c a$ & - & - \\
\hline
\end{tabular}

Table 5. Field Measurements of $M_{1}$ for the Actual Small-Scale PLC-based AMI.

\begin{tabular}{|c|c|c|c|c|c|c|c|}
\hline Day & $\begin{array}{c}\text { Number of } \\
\text { Reading } \\
\text { Success }\end{array}$ & $\begin{array}{l}\text { Reading } \\
\text { Success } \\
\text { Rate }(\%)\end{array}$ & $\begin{array}{l}\text { Response } \\
\text { Time (ms) }\end{array}$ & Day & $\begin{array}{c}\text { Number of } \\
\text { Reading } \\
\text { Success }\end{array}$ & $\begin{array}{l}\text { Reading } \\
\text { Success } \\
\text { Rate }(\%)\end{array}$ & $\begin{array}{l}\text { Response } \\
\text { Time (ms) }\end{array}$ \\
\hline 1 & 96 & 100.00 & 381.2 & 17 & 96 & 100.00 & 215 \\
\hline 2 & 96 & 100.00 & 620 & 18 & 84 & 87.50 & 148.6 \\
\hline 3 & 82 & 85.42 & 421.4 & 19 & 65 & 67.71 & 401.7 \\
\hline 4 & 96 & 100.00 & 358.7 & 20 & 77 & 80.21 & 261.7 \\
\hline 5 & 96 & 100.00 & 418.8 & 21 & 84 & 87.50 & 320 \\
\hline 6 & 96 & 100.00 & 293.8 & 22 & 77 & 80.21 & 510 \\
\hline 7 & 96 & 100.00 & 218.8 & 23 & 84 & 87.50 & 364.3 \\
\hline 8 & 96 & 100.00 & 260 & 24 & 77 & 80.21 & 361.7 \\
\hline 9 & 96 & 100.00 & 341.3 & 25 & 73 & 76.04 & 178.6 \\
\hline 10 & 96 & 100.00 & 366.3 & 26 & 96 & 100.00 & 240 \\
\hline 11 & 84 & 87.50 & 400 & 27 & 96 & 100.00 & 547.5 \\
\hline 12 & 77 & 80.21 & 178.3 & 28 & 96 & 100.00 & 386.3 \\
\hline 13 & 96 & 100.00 & 493.8 & 29 & 96 & 100.00 & 205 \\
\hline 14 & 84 & 87.50 & 205.7 & 30 & 96 & 100.00 & 258.7 \\
\hline 15 & 27 & 28.13 & 368.6 & 31 & 96 & 100.00 & 297.5 \\
\hline 16 & 46 & 47.92 & 260 & - & - & - & - \\
\hline
\end{tabular}

\section{Response Time}

$$
\mu_{R T}(\bullet)
$$

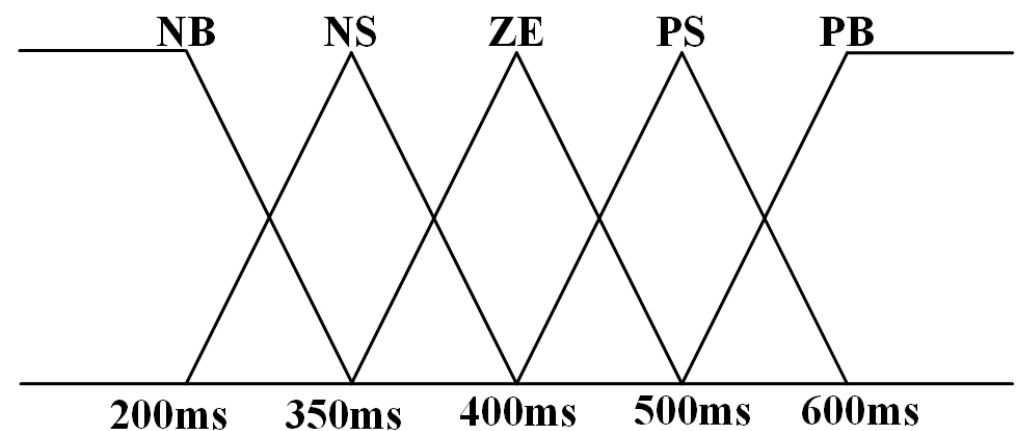

Figure 16. Membership Function of Response Time for Actual Small-Scale PLC-based AMI. 


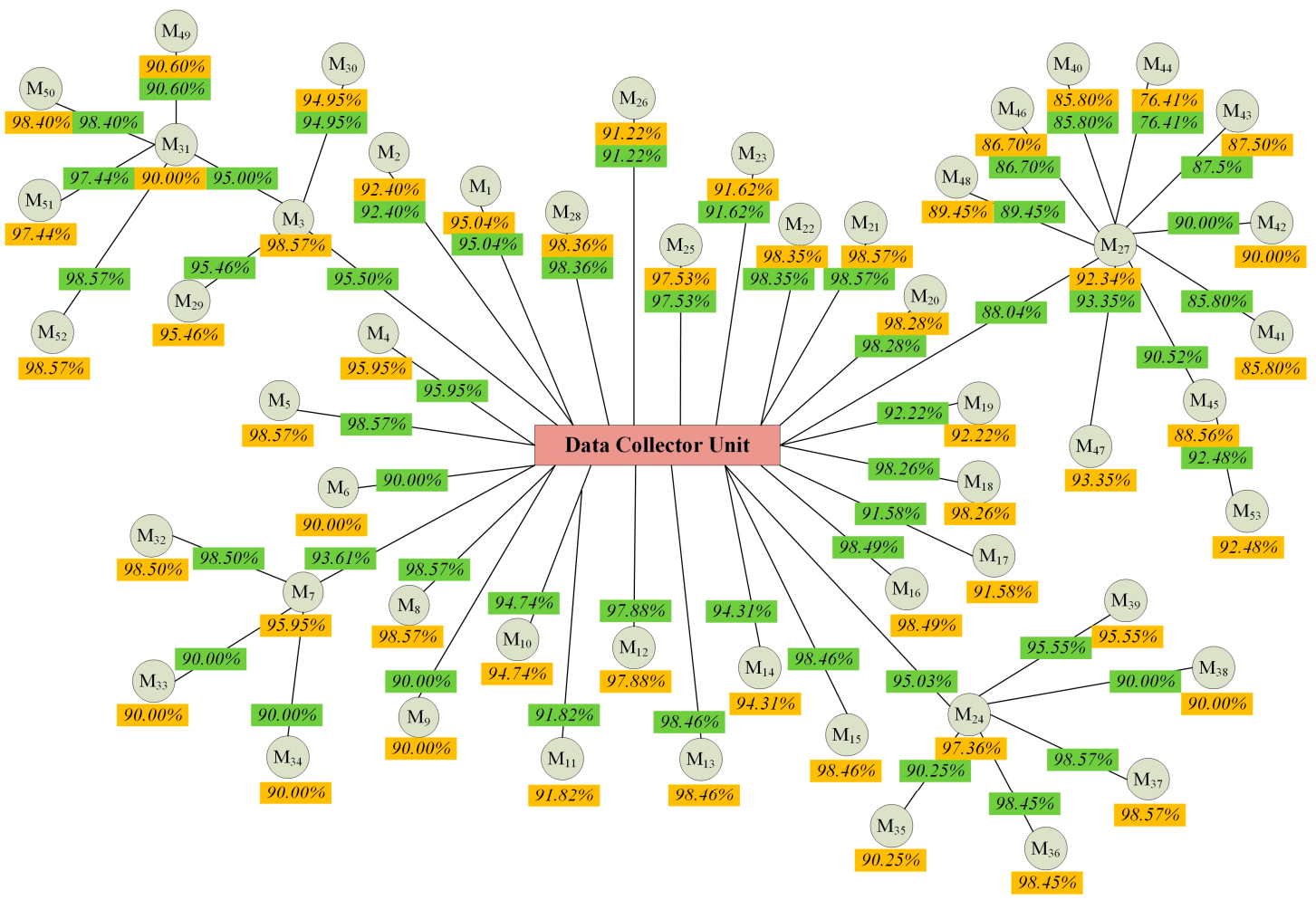

Figure 17. Calculated CPIs of Day 1 for Actual Small-Scale PLC-based AMI.

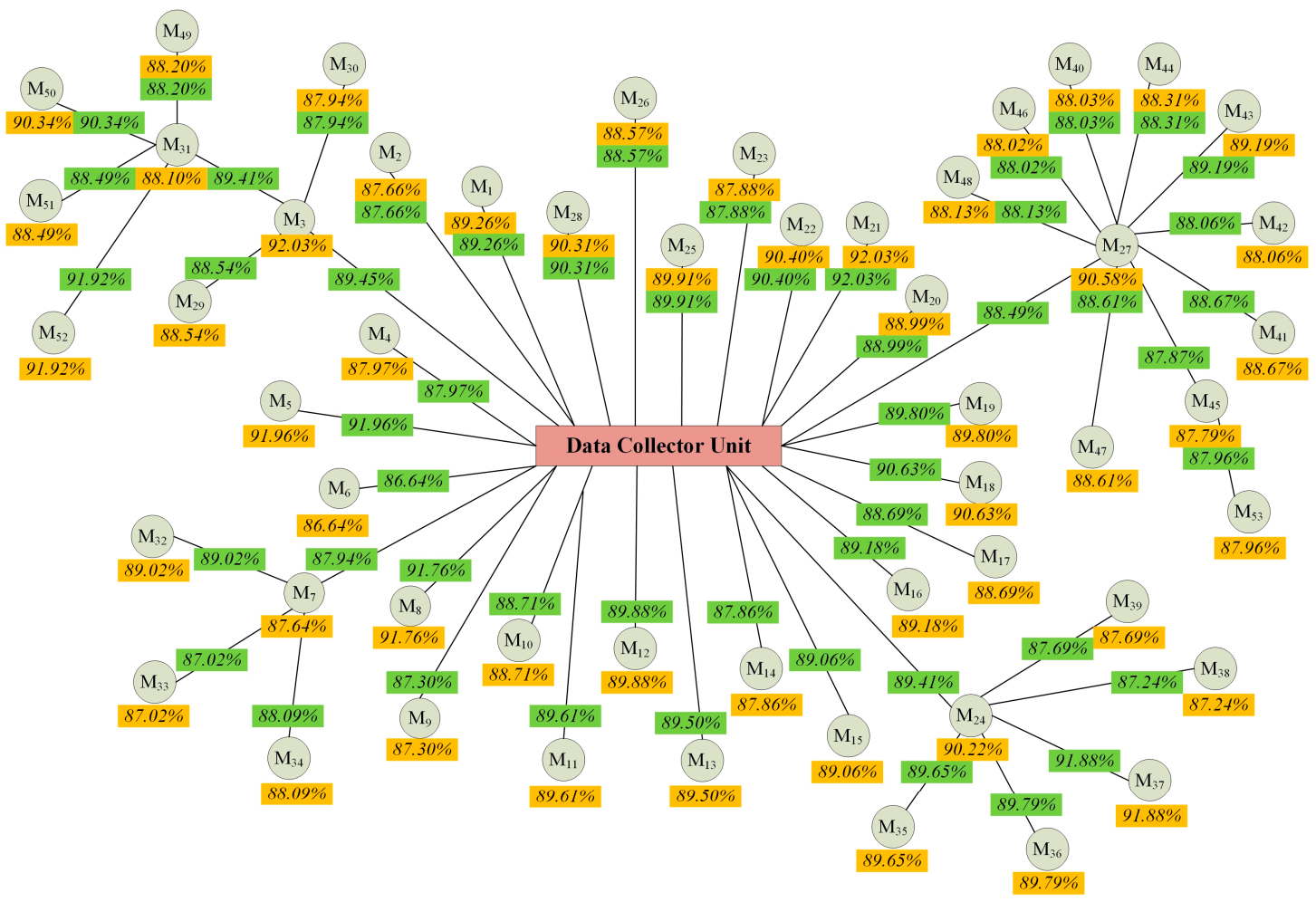

Figure 18. Calculated Average CPIs from Days 1 to 31 for Actual Small-Scale PLC-based AMI. 
Table 6. Average and Standard Deviation of Meter CPIs for the Actual Small-Scale PLC-based AMI.

\begin{tabular}{|c|c|c|c|c|c|c|c|c|}
\hline Meter & $\begin{array}{c}\text { Average } \\
\text { of CPI } \\
(\%)\end{array}$ & $\begin{array}{c}\text { Standard } \\
\text { Deviation of } \\
\text { CPI (\%) }\end{array}$ & Meter & $\begin{array}{c}\text { Average } \\
\text { of CPI } \\
(\%)\end{array}$ & $\begin{array}{c}\text { Standard } \\
\text { Deviation of } \\
\text { CPI (\%) }\end{array}$ & Meter & $\begin{array}{c}\text { Average } \\
\text { of CPI } \\
(\%)\end{array}$ & $\begin{array}{c}\text { Standard } \\
\text { Deviation of } \\
\text { CPI (\%) }\end{array}$ \\
\hline 1 & 89.26 & 9.63 & 19 & 89.80 & 10.05 & 37 & 91.88 & 9.29 \\
\hline 2 & 87.66 & 10.66 & 20 & 88.99 & 10.27 & 38 & 87.24 & 9.94 \\
\hline 3 & 92.03 & 9.36 & 21 & 92.03 & 9.31 & 39 & 87.69 & 10.50 \\
\hline 4 & 87.97 & 10.09 & 22 & 90.40 & 9.29 & 40 & 88.03 & 10.09 \\
\hline 5 & 91.96 & 9.32 & 23 & 87.88 & 8.59 & 41 & 88.67 & 10.74 \\
\hline 6 & 86.64 & 10.28 & 24 & 90.22 & 10.02 & 42 & 88.06 & 9.49 \\
\hline 7 & 87.64 & 10.91 & 25 & 89.91 & 9.23 & 43 & 89.19 & 10.00 \\
\hline 8 & 91.76 & 9.29 & 26 & 88.57 & 9.42 & 44 & 88.31 & 10.12 \\
\hline 9 & 97.30 & 10.50 & 27 & 90.57 & 8.80 & 45 & 87.79 & 9.69 \\
\hline 10 & 88.71 & 10.55 & 28 & 90.31 & 9.12 & 46 & 88.02 & 9.7 \\
\hline 11 & 89.61 & 9.52 & 29 & 88.54 & 9.85 & 47 & 88.61 & 10.00 \\
\hline 12 & 89.88 & 10.91 & 30 & 87.94 & 10.20 & 48 & 88.13 & 10.62 \\
\hline 13 & 89.50 & 9.75 & 31 & 88.10 & 10.64 & 49 & 88.20 & 8.91 \\
\hline 14 & 87.86 & 10.17 & 32 & 89.02 & 10.32 & 50 & 90.34 & 9.41 \\
\hline 15 & 89.06 & 10.59 & 33 & 87.02 & 10.09 & 51 & 88.49 & 10.17 \\
\hline 16 & 89.18 & 9.71 & 34 & 88.09 & 9.18 & 52 & 91.92 & 9.30 \\
\hline 17 & 88.69 & 8.82 & 35 & 89.65 & 9.09 & 53 & 87.96 & 10.13 \\
\hline 18 & 90.63 & 9.03 & 36 & 89.79 & 9.37 & & & \\
\hline
\end{tabular}

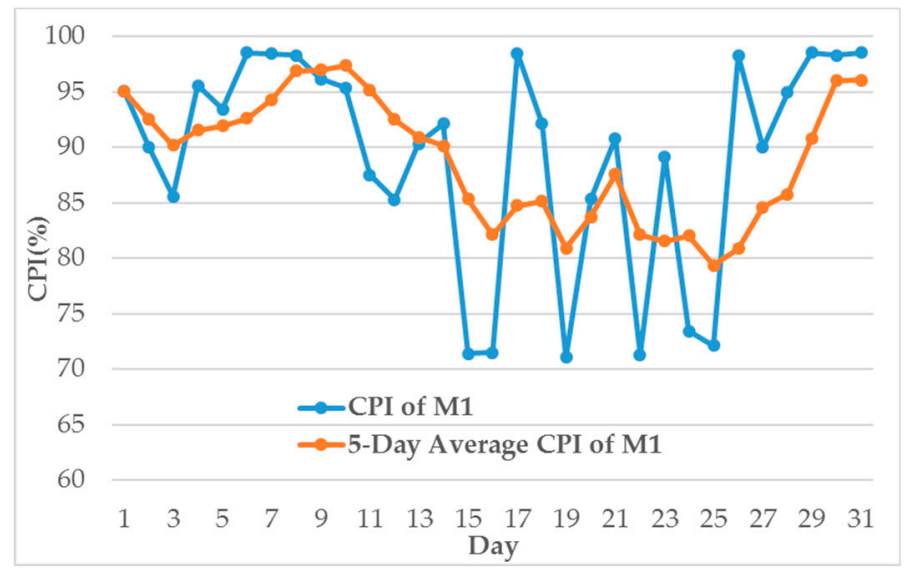

Figure 19. CPIs and 5-Day Average CPIs of Smart Meter $M_{1}$.

\section{Conclusions}

If the communication performance and stability is poor, all AMI functionalities cannot be effectively realized. Therefore, communication performance and stability between widely-spread smart meters and DCUs should be assessed and supervised for the successful deployment and operation of AMI. An effective CPI used to assess and supervise the communication performance of each smart meter was proposed in this paper. Reading success rate and response time were used to design the proposed CPI. A higher reading success rate usually indicates better stability of the communication network. A faster response time implies a higher communication performance. Fuzzy logic was adopted to integrate these measurements to calculate the proposed CPI. The CPIs for communication paths, DCUs and whole AMI can then be obtained from meter CPIs. Simulation results were used to clarify the basic concepts and implementation of proposed CPI. The field communication measurements acquired from an actual small-scale PLC-based AMI were used to demonstrate the validity of the proposed CPI. From experimental results, it can be observed that the CPIs for each meter and communication path can be assessed and supervised. Long-term monitoring of CPIs for meters, DCUs and communication paths, will be able to identify the weaknesses of communication network and be supportive of the operation of AMI. Other communication factors such as the link quality indicator, received signal strength indicator, signal-to-noise ratio etc. can also be measured and 
integrated into the proposed CPI and will be further investigated. The proposed CPI can also be used to access and supervise the communication performance of smart cities and will also be studied in future research.

Author Contributions: J.-H.T., C.-W.C. and B.-H.L. proposed and designed the effective and efficient CPI for AMI. J.-H.T., C.-W.C., B.-H.L., W.-H.H. and J.-C.C. worked together to collect the filed measurements of the actual small-scale PLC-based AMI and finished the simulation and experimental results for the communication performance assessment of AMI.

Acknowledgments: This research was financially supported by the "Project for Research on International Energy Policy and Technologies Development on AMI Value-Added Services" of the Institute for Information Industry subsidized by the Ministry of Economy Affairs of Taiwan and Ministry of Science and Technology of Taiwan under Contracts MOST 107-3113-E-110-001 and MOST 104-2221-E-110-042-MY3.

Conflicts of Interest: The authors declare no conflicts of interest.

\section{References}

1. Samad, T.; Annaswamy, A.M. Controls for smart grids: Architectures and applications. Proc. IEEE 2017, 105, 2244-2261. [CrossRef]

2. Masera, M.; Bompard, F.E.; Profumo, F.; Hadjsaid, N. Smart (electricity) grids for smart cities: Assessing roles and societal impacts. Proc. IEEE 2018, 106, 613-625. [CrossRef]

3. Collier, S.E. Ten steps to a smarter grid. IEEE Ind. Appl. Mag. 2010, 16, 62-68. [CrossRef]

4. Liu, W.-H.E. Analytics and information integration for smart grid applications. In Proceedings of the IEEE Power and Energy Society General Meeting, Detroit, MI, USA, 24-29 July 2010; pp. 1-3.

5. Farhangi, H. The path of the smart grid. IEEE Power Energy Mag. 2010, 8, 18-28. [CrossRef]

6. "Global Smart Meter Market Expected to See Huge Rollout". GlobalData Energy. Available online: https:// www.power-technology.com/comment/global-smart-meter-market-expected-see-huge-rollout/ (accessed on 17 September 2018).

7. “Advanced Metering Infrastructure Market Research Report-Global Forecast to 2023". Half-Cooked Research Reports. Available online: https:/ / www.marketresearchfuture.com/reports/advanced-meteringinfrastructure-market-5185 (accessed on 20 November 2018).

8. Strother, N.; Lockhart, B. Smart Electric Meters, Advanced Metering Infrastructure, and Meter Communications: Global Market Analysis and Forecasts; Navigant Research: Boulder, CO, USA, 2014.

9. Uribe-Pérez, N.; Hernández, L.; de la Vega, D.; Angulo, I. State of the Art and Trends Review of Smart Metering in Electricity Grids. Appl. Sci. 2016, 6, 68. [CrossRef]

10. Ghosal, A.; Conti, M. Key Management Systems for Smart Grid Advanced Metering Infrastructure: A Survey. arXiv 2018, arXiv:1806.00121v1.

11. Sial, A.; Singh, A.; Mahanti, A.; Gong, M. Heuristics-Based Detection of Abnormal Energy Consumption. In Proceedings of the SmartGIFT 2018: Smart Grid and Innovative Frontiers in Telecommunications, Auckland, New Zealand, 23-24 April 2018; pp. 21-31.

12. Yan, Y.; Qian, Y.; Sharif, H.; Tipper, H. A Survey on Smart Grid Communication Infrastructures: Motivations, Requirements and Challenges. IEEE Commun. Surv. Tutor. 2013, 15, 5-20. [CrossRef]

13. Matanza, J.; Alexandres, S.; Rodriguez-Morcillo, C. Advanced metering infrastructure performance using European low-voltage power line communication networks. IET Commun. 2014, 8, 1041-1047. [CrossRef]

14. Chi, H.R.; Tsang, K.F.; Chui, K.T.; Chung, S.H.; Ling, B.W.K.; Lai, L.L. Interference-mitigated ZigBee-based advanced metering Infrastructure. IEEE Trans. Ind. Inform. 2016, 12, 672-684. [CrossRef]

15. Artale, G.; Cataliotti, A.; Cosentino, V.; Cara, D.; Fiorelli, R.; Guaiana, S.; Panzavecchia, N.; Tinè, G. A new PLC-based smart metering architecture for medium/low voltage grids: Feasibility and experimental characterization. Measurement 2018, 129, 479-488. [CrossRef]

16. Aalamifar, F.; Lampe, L. Optimized data acquisition point placement for an advanced metering infrastructure based on power line communication technology. IEEE Access 2018, 6, 45347-45358. [CrossRef]

17. Ancillotti, E.; Bruno, R.; Conti, M. The role of the RPL routing protocol for smart grid communications. IEEE Commun. Mag. 2013, 51, 75-83. [CrossRef]

18. Yang, Z.; Ping, S.; Sun, H.; Aghvami, A.H. CRB-RPL: A receiver-based routing protocol for communications in cognitive radio enabled smart grid. IEEE Trans. Veh. Technol. 2017, 66, 5985-5994. [CrossRef] 
19. Malandra, F.; Sansò, B. A Markov-modulated end-to-end delay analysis of large-scale RF mesh networks with time-slotted ALOHA and FHSS for smart grid applications. IEEE Trans. Wirel. Commun. 2018, 17, 7116-7127. [CrossRef]

20. Gentile, C.; Griffith, D.; Souryal, M. Wireless network deployment in the smart grid: Design and evaluation issues. IEEE Netw. 2012, 26, 48-53. [CrossRef]

21. Jiang, J.; Qian, Y. Distributed communication architecture for smart grid applications. IEEE Commun. Mag. 2016, 54, 60-67. [CrossRef]

22. Ramírez, D.F.; Céspedes, S.; Becerra, C.; Lazo, C. Performance evaluation of future AMI applications in Smart Grid Neighborhood Area Networks. In Proceedings of the IEEE Colombian Conference on Communication and Computing (IEEE COLCOM 2015), Popayán, Colombia, 13-15 May 2015; pp. 1-6.

23. Malandra, F.; Sanso, B. PeRF-Mesh: A performance analysis tool for large scale RF-mesh-based smart meter networks with FHSS. In Proceedings of the 2015 IEEE International Conference on Smart Grid Communications (SmartGridComm), Miami, FL, USA, 2-5 November 2015; pp. 792-797.

24. Vondrouš, O.; Macejko, P.; Hégr, T.; Kocur, Z. Testing methodology for performance evaluation of communication systems for smart grid. In Proceedings of the 20162 nd International Conference on Intelligent Green Building and Smart Grid (IGBSG), Prague, Czech Republic, 27-29 June 2016; pp. 1-6.

25. Argoneto, P.; Renna, P. Capacity sharing in a network of enterprises using the Gale-Shapley model. Int. J. Adv. Manuf. Technol. 2013, 69, 1907-1916. [CrossRef]

26. Liu, Y.K.; Zhang, L.; Tao, F.; Wang, L. Resource service sharing in cloud manufacturing based on the Gale-Shapley algorithm: Advantages and challenge. Int. J. Comput. Integr. Manuf. 2017, 30, 420-432.

27. Zadeh, L.A. The concept of a linguistic variable and its applications to approximate reasoning-I. Inf. Sci. 1975, 8, 199-249. [CrossRef]

28. Zadeh, L.A. The concept of a linguistic variable and its applications to approximate reasoning-II. Inf. Sci. 1975, 8, 301-357. [CrossRef]

29. Teng, J.H.; Liao, S.H.; Wen, C.K. Design of a fully decentralized controlled electric vehicle charger for mitigating charging impact on power grids. IEEE Trans. Ind. Appl. 2017, 52, 1497-1505. [CrossRef]

30. Hannan, M.A.; Ghani, Z.A.; Mohamed, A.; Uddin, M.N. Real-time testing of a fuzzy-logic-controller-based grid-connected photovoltaic inverter system. IEEE Trans. Ind. Appl. 2015, 51, 4775-4784. [CrossRef]

31. Chang, E.J.; Hsin, H.K.; Lin, S.Y.; Wu, A.Y. Path-congestion-aware adaptive routing with a contention prediction scheme for network-on-chip systems. IEEE Trans. Comput.-Aided Des. Integ. Circuits Syst. 2014, 33, 113-126. [CrossRef]

32. Wu, D.; Ci, S.; Wang, H.H.; Katsaggelos, A.K. Application-centric routing for video streaming over multi-hop wireless networks. IEEE Trans. Circuits Syst. Video Technol. 2010, 20, 1721-1734. [CrossRef]

33. Ma, K.; Liu, X.; Yang, J.; Liu, Z.; Yuan, Y. Optimal Power Allocation for a Relaying-Based Cognitive Radio Network in a Smart Grid. Energies 2017, 10, 909. [CrossRef] 